\title{
Preparations, properties and applications of chitosan based nanofibers fabricated by electrospinning
}

\author{
K. Sun ${ }^{*}$, Z. H. $\mathrm{Li}$ \\ Deparment of chemistry, Sichuan college of education, Chendu 610041, Sichuan province, China
}

Received 5 September 2010; accepted in revised form 14 November 2010

\begin{abstract}
Chitosan is soluble in most acids. The protonation of the amino groups on the chitosan backbone inhibits the electrospinnability of pure chitosan. Recently, electrospinning of nanofibers based on chitosan has been widely researched and numerous nanofibers containing chitosan have been prepared by decreasing the number of the free amino groups of chitosan as the nanofibiers have enormous possibilities for better utilization in various areas. This article reviews the preparations and properties of the nanofibers which were electrospun from pure chitosan, blends of chitosan and synthetic polymers, blends of chitosan and protein, chitosan derivatives, as well as blends of chitosan and inorganic nanoparticles, respectively. The applications of the nanofibers containing chitosan such as enzyme immobilization, filtration, wound dressing, tissue engineering, drug delivery and catalysis are also summarized in detail.
\end{abstract}

Keywords: nanomaterials, chitosan, nanofibers, electrospinning, applications

\section{Introduction}

Electrospinning is a fiber-forming process by which either polymer solutions or melts are charged by high voltage to form fine jets. It was first reported by Formhals in 1934 [1]. Fiber formation by electrospinning of polymer solutions has been extensively studied in terms of voltage, tip-to-collector distance, feeding rate of polymer solution, and polymer solution properties [2-5]. These nanofibers can form nonwoven textile mats, oriented fibrous bundles and even three-dimensional structured scaffolds, all with large surface areas and high porosity [6]. These nanofibers are of considerable interest for various kinds of applications.

Chitosan, a (1-4)-linked 2-amino-2-deoxy-D-glucopyranose (Figure 1), is derived from chitin, one of the most abundant natural polysaccharides. Chitosan is well known for its nontoxic, biocompatible and biodegradable properties [7]. In addition, it has several unique properties: it is antimicrobial and inhibits the growth of a wide variety of fungi, yeasts, and bacteria, which can be beneficial for use in the field of biomedicine [8]. It can also bind toxic metal ions, which can be beneficial for use in air cleaning and water purification applications [9]. These properties arise as a result of protonation of $\mathrm{NH}_{2}{ }^{-}$groups on the chitosan backbone.

Recently, electrospun nanofibers based on chitosan have been widely researched and various nanofiber products containing chitosan have been produced by electrospinning. These nanofibers yield potential applications in various areas. This article reviews the preparations and properties of the nanofibers by electrospinning of pure chitosan, blends of chitosan and synthetic polymers, blends of chitosan and pro-

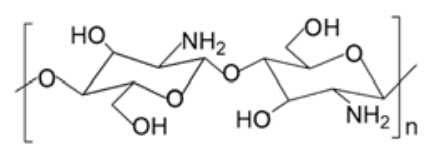

Figure 1. The molecular structure of chitosan

\footnotetext{
${ }^{*}$ Corresponding author, e-mail: kang-sun@163.com

(c) BME-PT
} 
tein, chitosan derivatives, as well as blends of chitosan and inorganic nanoparticles, respectively. The applications of the chitosan based nanofibers in areas such as enzyme immobilization, filtration, wound dressing, tissue engineering, drug delivery and catalysis are also summarized in detail.

\section{Electrospinning of chitosan}

\subsection{Electrospinning of pure chitosan}

Chitosan is soluble in most acids. The protonation of chitosan changes it into a polyelectrolyte in acidic solutions. The repulsive forces between ionic groups within polymer backbone that arise due to the application of a high electric field during electrospinning restrict the formation of continuous fibers and often produce beads [10], so it is difficult to fabricate pure chitosan nanofibers. An electrospun nanofibrous mat of pure chitosan was successfully prepared by Ohkawa and coworkers [11] using trifluoroacetic acid (TFA) as electrospinning solvent. TFA is a suitable spinning solvent for chitosan because the amino groups of the chitosan can form salts with TFA [12], which can effectively destroy the intermolecular interactions between the chitosan molecules and thus facilitate electrospinning. As the chitosan concentration increases, the morphology of the deposition on the collector changes from spherical beads to interconnected fibrous networks. The addition of dichloromethane (DCM) to the chitosan-TFA solution improves the homogeneity of the electrospun chitosan fibers without interconnected fibrous networks. Under optimized conditions, homogenous chitosan fibers with a mean diameter of $330 \mathrm{~nm}$ were prepared. Another study conducted by Ohkawa et al. [13] focused on optimizing the viscosity of chitosan solutions in order to decrease the average fiber diameter. It was determined that fiber diameter and polymer concentration have an inverse relationship. Sangsanoh et al. [14] developed electrospun chitosan nanofibers using TFA/DCM $(70: 30 \mathrm{v} / \mathrm{v})$ as electrospinning solvent. The obtained fibers with average diameters of $126 \pm 20 \mathrm{~nm}$ were smooth without the presence of beads.

Dissolution of chitosan nanofibers by electrospinning of chitosan solution in TFA with or without DCM as the modifying cosolvent will result in the loss of the fibrous structure as soon as the membranes contact with neutral or weak basic aqueous solutions, and thus limits the further use of the membranes [15]. Dissolution occurs as a result of the high solubility in these aqueous media of $-\mathrm{NH}_{3}{ }^{+} \mathrm{CF} 3 \mathrm{COO}^{-}$salt residues that are formed when chitosan is dissolved in TFA. Traditional neutralization with a $\mathrm{NaOH}$ aqueous solution only maintained partial fibrous structure. Much improvement in the neutralization method was achieved with the saturated $\mathrm{Na}_{2} \mathrm{CO}_{3}$ aqueous solution with an excess amount of $\mathrm{Na}_{2} \mathrm{CO}_{3}(\mathrm{~s})$ in the solution. The electrospun chitosan nanofibrous membranes, after neutralization in the $\mathrm{Na}_{2} \mathrm{CO}_{3}$ aqueous solution, could maintain its fibrous structure even after continuous submersion in phosphate buffer saline $(\mathrm{pH}=$ 7.4) or distilled water for 12 weeks. Haider and Park [16] prepared similar chitosan nanofiber mats by electrospinning. The as-spun nanofiber $(\sim 235 \mathrm{~nm}$ in diameter) mats which were neutralized with potassium carbonate showed good erosion stability in water and high adsorption affinity for metal ions in an aqueous solution.

Besides TFA, the second solvent that has shown to effectively produce chitosan nanofibers is concentrated acetic acid. A uniform nanofibrous mat with average fiber diameter of $130 \mathrm{~nm}$ was fabricated by Geng et al. [17] from the following optimum condition: $7 \%$ chitosan solution in aqueous $90 \%$ acetic acid solution and in the electric field of $4 \mathrm{kV} / \mathrm{cm}$. The aqueous acetic acid concentration higher than $30 \%$ was a prerequisite for chitosan nanofiber formation, because more concentrated acetic acid in water progressively decreased the surface tension of the chitosan solution and concomitantly increased the charged density of jet without a significant effect on the solution viscosity. However, acetic acid solution of more than $90 \%$ did not dissolve enough chitosan to make a spinnable viscous concentration. Additionally, only chitosan of a molecular weight of $106000 \mathrm{~g} / \mathrm{mol}$ produced bead-free chitosan nanofibers, while low or high molecular weight chitosans of 30000 and $398000 \mathrm{~g} / \mathrm{mol} \mathrm{did}$ not. Average fiber diameters and size distribution decreased with increasing electric field and more bead defects appeared at $5 \mathrm{kV} / \mathrm{cm}$ or more. In addition, Vrieze et al. [18] attempted a range of acid aqueous solutions such as formic acid, acetic acid, lactic acid and hydrochloric acid for developing chitosan nanofibres by electrospinning. The study showed that chitosan nanofibres with a diameter of 
about $70 \pm 45 \mathrm{~nm}$ were obtained from a concentrated acetic acid solution $(90 \%)$ with a $3 \%$ chitosan concentration at an applied voltage of $2.0 \mathrm{kV} / \mathrm{cm}$ and a flow rate of $0.3 \mathrm{ml} / \mathrm{h}$.

The problem of the high viscosity of chitosan, which limits its spinnability, is resolved through the application of an alkali treatment which hydrolyzes chitosan chains and so decreases their molecular weight [19]. Solutions of the treated chitosan in aqueous $70-90 \%$ acetic acid produce nanofibers with appropriate quality and processing stability. Decreasing the acetic acid concentration in the solvent increases the mean diameter of the nanofibers. Optimum nanofibers are achieved with chitosan which is hydrolyzed for $48 \mathrm{~h}$. Such nanofibers result in a moisture regain which is $74 \%$ greater than that of treated and untreated chitosan powder. The diameter of this nanofiber, $140 \mathrm{~nm}$, is strongly affected by the electrospinning conditions as well as by the concentration of the solvent. FTIR investigations prove that neither the alkali treatment nor the electrospinning process change the chemical nature of the polymer.

Pure chitosan nanofibers can be cross-linked using a method involving glutaraldehyde (GA) vapor, utilizing a Schiff base imine functionality. The study conducted by Schiffman et al. [20] indicated that the solubility of the chitosan mats was greatly improved after cross-linking. The as-spun medium molecular weight chitosan nanofibers have a Young's modulus of $154.9 \pm 40.0 \mathrm{MPa}$, and were highly soluble in acidic and aqueous solutions. After cross-linking, the fibers increased in diameter by an average of $161 \mathrm{~nm}$, have a decreased Young's modulus of $150.8 \pm 43.6 \mathrm{MPa}$, and were insoluble in basic, acidic, and aqueous solutions. Though the extent to which GA penetrates into the chitosan fibers is currently unknown, it is evident that the cross-linking resulted in increased brittleness, a color change, and the restriction of fiber sliding. Schiff base cross-linked chitosan fibrous mats can be produced utilizing a one-step electrospinning process [21], which is 25 times faster and, therefore, more economical than the two-step vaporcross-linking method mentioned above. These fibrous mats are insoluble in acidic, basic, and aqueous solutions for $72 \mathrm{~h}$. Additionally, this improved production method results in a decreased average fiber diameter, which measures $128 \pm 40 \mathrm{~nm}$.

\subsection{Electrospinning of blends of chitosan and synthetic polymers}

It is commonly observed when electrospinning from polymers that the formation of beads attributed to an inadequate stretch of the filaments during the whipping of the jet because of a low charge density. To overcome this defect, salts [22], ionic surfactants [23] or ionic polyelectrolytes [24] can be added into the polymer solution to improve the net charge density that enhances the whipping instability. The jet was stretched under stronger charge repulsion and at a higher speed, resulting in an exhaustion of the bead structure. Since chitosan is a linear cationic polymer, it was determined that chitosan can act like other ionic additives and reduce fiber diameter and thus producing bead free fibers [25]. Recently, the electrospun composite nanofibers have been developed using chitosan and synthetic polymers such as poly(vinyl alcohol) (PVA), poly(ethylene oxide) (PEO), poly(ethylene terpthalate) (PET), polycaprolactone (PCL), poly(lactic acid) (PLA), nylon-6 and others. These composite nanofibers are more advantageous over the electrospun nanofibers of pure chitosan, because the mechanical, biocompatible, antibacterial and other properties of the nanofibers were drastically enhanced by the addition of these polymers.

Because of its favorable properties such as nontoxicity, biocompatibility and biodegradability, PVA has been used for a variety of biomedical applications such as bone implants as a replacement for the nucleus pulposus [26] and artificial organs [27]. Because PVA has good fiber forming characteristics, many nanofibers of the blends of PVA and chitosan have been fabricated by electrospinning [2833]. For examples, Nanofibers with average diameters between 20 and $100 \mathrm{~nm}$ have been prepared by electrospinning of $82.5 \%$ deacetylated chitosan $\left(M_{\mathrm{v}}=1600 \mathrm{kDa}\right)$ mixed with poly(vinyl alcohol) (PVA, $\left.M_{\mathrm{w}}=124-186 \mathrm{kDa}\right)$ in $2 \%(\mathrm{v} / \mathrm{v})$ aqueous acetic acid [28]. Finer fibers, fewer beaded structures and more efficient fiber formation were observed with increasing PVA contents. Chitosan/ PVA nanofibers were also prepared via the electrospinning of chitosan/PVA/acrylic acid aqueous solutions at various concentrations by adjusting the concentrations of chitosan, PVA and acrylic acid [29]. The nanoporous fibers of pure chitosan could be generated by removing the PVA component in the 
chitosan/PVA bicomponent fibers with $\mathrm{NaOH}$ aqueous solution $[28,30]$. These pure chitosan nanofibers have special characteristics of excellent biocompatibility, high surface/volume ratio, and large porosity. Chitosan/PVA nanofibers can be crosslinked with heat mediated chemical crosslinking [34]. Triethylene glycol dimethacrylate (TEGDMA ) was added into chitosan/PVA solution prior to spinning followed by heat-treating the as-spun mats for $2 \mathrm{~h}$ at $80^{\circ} \mathrm{C}$. The results showed that, the nanofibers exhibited a smooth surface and regular morphology, and tensile strength of nanofibers improved with increasing of TEGDMA content.

Poly(ethylene oxide) (PEO) is also a biocompatible polymer that has been used as cartilage tissue repair [35] and wound dressing [36]. Many nanofibers of the blends of PEO and chitosan have also been fabricated by electrospinning [37-42]. For examples, Klossner et al. [37] fabricated defect-free nanofibers with average diameters ranging from $62 \pm 9$ to $129 \pm 16 \mathrm{~nm}$ by electrospinning of blended solutions of chitosan and PEO in acetic acid. Their study showed that as total polymer concentration (chitosan + PEO) increased, the number of beads decreased, and as chitosan concentration increased, fiber diameter decreased. Chitosan/PEO solutions phase would separate over time, so blended solutions were able to be electrospun easily within $24 \mathrm{~h}$ of initially being blended. The addition of $\mathrm{NaCl}$ stabilized these solutions and increased the time the blended solutions could be stored before electrospinning. Bhattarai et al. [38] prepared nanofibers with an average fiber diameter controllable from a few microns down to $\sim 40 \mathrm{~nm}$ and a narrow size distribution by electrospinning solutions containing chitosan, PEO and Triton $\mathrm{X}-100^{\mathrm{TM}}$. It was found that the matrix with a chitosan/PEO ratio of 90/10 retained excellent integrity of the fibrous structure in water. Hybrids of chitosan/PEO could be electrospun in the presence of micellar surfactant solutions $[39,40]$. The presence of surfactants resulted in the formation of needle-like, smooth or beaded fibers. It was revealed that nanofibers consisted of both polymers and surfactants with concentration of the constituents differing from that in polymer solutions. Results suggest that surfactants may modulate polymer-polymer interactions thus influencing the morphology and composition of deposited nanostructures. Introduction of an ultrahigh-molec- ular-weight poly(ethylene oxide) (UHMWPEO) into aqueous chitosan solutions remarkably enhances the formation of chitosan nanofibrous structure and leads to much lower loading of the water soluble fiber [43]. It can be made into both extremely thin nanofibers (less than $100 \mathrm{~nm}$ in diameters) and large microfibers (few tens of micrometers in diameters). The excellent electrospinnability of the current formulation renders electrospinning of natural biopolymer chitosan a robust process for largescale production of practically applicable nanofibrous structures.

Polyethylene terephthalate (PET) is a highly crystalline polymer with excellent physical, mechanical and antibacterial properties [44], and is often used in the textile and plastic industry. The polymer blends of PET and chitosan could be electrospun onto the PET micro-nonwoven mats for biomedical applications [45]. The PET/chitosan nanofibers were evenly deposited on to the surface, and the diameter of the nanofibers was in the range between 500 and $800 \mathrm{~nm}$. The wettability and antibacterial activity of the PET nanofibers was significantly enhanced by the incorporation of chitosan. Lopes-da-Silva et al. [46] also reported the preparation and characterization of nanofibrous mats electrospun from mixed solutions of PET and chitosan. Their results indicated that the presence of chitosan increased the diameter and the size distribution of the fibers. Chitosan molecular weight and concentration affected the mechanical properties of the nanofibrous mats. Phase separation during solvent evaporation and fiber formation, taking place at varied extent depending on molecular mobility of one of the components, is suggested to explain the formation of hybrid continuous or core-sheath fibers.

Polycaprolactone (PCL) is a semi-crystalline polymer with good flexibility, it can be used as surgical sutures, fracture fixation materials and drug carrier. PCL nanofibers containing various amounts of chitosan $(0,3,9$, and $23 \%)$ were prepared [47]. Characterization of the obtained nanofibers revealed that average fiber diameter, hydrophilicity, Young's modulus, and fiber degradation were all closely correlated with the amount of chitosan in PCL nanofibers. The nanofibers are superior to PCL nanofibers in promoting bone tissue formation. Another fibrous scaffold comprising of chitosan and PCL was electrospun in a novel solvent consisting of 
formic acid and acetone [48]. This study indicated that optimized combination of chitosan $(1 \%)$ and PCL $(8 \%)$ was in 1:3 compositions. Mohammadi et al. [49] also developed 3D PCL nanofibrous scaffolds containing chitosan and PVA for bone tissue engineering via a multi-jet electrospinning method. Poly(lactic acid)(PLA) is a thermoplastic polymer made from lactic acid and has mainly been used for biodegradable products, such as plastic bags and planting cups [50]. The chitosan/PLA blend micro/ nanofibers have been prepared by electrospinning in TFA [51]. It was found that the average diameter of the chitosan/PLA blend fibers became larger, and the morphology of the fibers became finer with the content of PLA increasing. Fourier transform infrared spectroscopy (FTIR) indicated that there are molecular interactions between chitosan and PLA. Chen et al. [52] prepared Chitosan/poly(L-lactic acid-co$\varepsilon$-caprolactone) (P(LLA-CL)) blend nanofibers by electrospining using 1,1,1,3,3,3-hexafluoro-2propanol (HFIP) and TFA as solvents. The average fiber diameter increased with increasing polymer concentration and decreasing the blend ratio of chitosan to P(LLA-CL). The porosity of chitosan/ $\mathrm{P}($ LLA-CL) nanofiber mats increased with increasing the weight ratio of chitosan to P(LLA-CL), while both the tensile strength and the ultimate strain increased with increasing P(LLA-CL) ratio. Nylon-6 (polyamide-6) has good mechanical properties and thermal stability, and has earlier been used as engineering plastics. Nylon-6 nonwoven mats have been produced from solutions with formic acid (FA) by electrospinning [53]. Composite membranes of nylon-6/chitosan nanofibers with different weight ratio of nylon-6 to chitosan were fabricated by electrospinning [54]. The morphology and diameter of the nanofibers were influenced by the concentration of the solution and weight ratio of the blending component materials. This study indicated that intermolecular interactions occurred between nylon- 6 and chitosan and the intermolecular interactions varied with varying chitosan content in the fibers. It was concluded that a new composite product was created and the stability of this system was attributed to strong new interactions such as hydrogen bond formation between the nylon- 6 polymers and chitosan structures.

Synthetic polymers which can improve the spinnability of chitosan have a same property that the poly- mers can interfere with the rigid association of the chitosan molecules, and thus lead to less free amino groups on the chitosan backbone. The addition of the polymers can relieve the protonation of chitosan restricting the formation of continuous fibers. Moreover, the polymers can be conveniently electrospun to nanofibers. Except for synthetic polymers, agarose, a natural polymer which has special gelling properties resulting in various applications [55], could improve the spinnability of chitosan with TFA/ DCM mixture as electrospinning solvent [56]. It was found that smooth, continuous fibers were generated at an agarose content of less than $50 \%$. The FTIR analysis revealed a gradual shift of the absorption band in the blend fibers, suggesting the strong interaction and good compatibility between chitosan and agarose.

\subsection{Electrospinning of blends of chitosan and proteins}

The proteins which can be mixed with chitosan to form electrospun nanofibers have similar characteristics with the polymers mentioned above: they can be conveniently electrospun to nanofibers and can interfere with the association of the chitosan molecules. Pure electrospun collagen nanofibers have been fabricated in HFIP [57]. The nanofibrous matrix is a good candidate for biomedical applications, such as wound dressing and scaffolds for tissue engineering. To develop better biomimetic wound dressing and extracellular matrix for the tissue engineering, electrospun collagen/chitosan nanofibrous mats were developed by electrospinning using HFIP/TFA (the volume ratio of 90/10) as solvent [58]. It was found that the diameter of the spun fibers became thick with the concentration of the solution increasing and became fine with the ratio of the chitosan/collagen increasing. The intermolecular interactions in electrospun collagen/chitosan complex fibers were also studied by Chen et al. [59]. Their study showed that intermolecular interactions existed and varied with various chitosan contents in the fibers. These interactions make collagen and chitosan miscible at the molecular level. The mechanical properties of electrospun collagen/chitosan single fibers and fibrous membrane investigated with a nano tensile testing system and a universal materials tester, respectively, were dependent on fiber diameter and the ratio of colla- 
gen to chitosan in fibers [60]. The collagen/chitosan nanofibers can be further crosslinked by glutaraldehyde (GA) vapor [61]. After crosslinking, the collagen/chitosan nanofibers do not change significantly, except for enhanced stability, neither collagen nor chitosan molecular chains could be crystallized in the course of electrospinning and crosslinking, and yielding an amorphous structure in the nanofibers. Blends of type I collagen, chitosan and PEO can be electrospun into nanofibers, which could be further crosslinked by glutaraldehyde (GA) vapor [62]. The nanofiber diameter was found to be $134 \pm 42 \mathrm{~nm}$, which increased to $398 \pm 76 \mathrm{~nm}$ after crosslinking. The Young's modulus increased after crosslinking, however, the ultimate tensile strength, tensile strain, and water sorption capability decreased after crosslinking.

Silk fibroin (SF) is the fibrous protein that forms silkworm silk. In recent years, SF has been increasingly studied for new biomedical applications due to its biocompatibility, slow degradability, remarkable mechanical properties, low inflammatory responses, and good oxygen and water vapor permeability of the material $[63,64]$. In addition, it was found that SF had a good anti-thrombogenicity and absorbability even though the polymer showed foreign body reaction [65]. Pure SF nanofibers can be made by electrospinning of SF in formic acid [66]. Similarly, SF/chitosan nanofibers can be made by electrospinning of $\mathrm{SF} /$ chitosan blends containing up to the chitosan content of $30 \%$ in formic acid [67]. The as-spun SF/chitosan blend nanofibers showed smaller diameter and narrower diameter distribution than pure SF nanofibers, and the diameter gradually decreased from 450 to $130 \mathrm{~nm}$ with the addition of chitosan in blends. Comparing with the pure SF nanofibers, the conformational change of the as-spun SF/chitosan blend nanofibers into $\beta$ sheet was faster because the chitosan with rigid backbone might synergistically promote the conformational transition of SF by an intermolecular interaction.

Zein is a 'yellowish' colored maize storage prolamine that induced great interest in a number of industrial applications such as food, food coating and food packaging, and can be easily electrospun into nanofibers [68]. Blends of zein and chitosan (up $10 \mathrm{wt. \% )}$ can be electrospun to yield water insoluble fiber mats with efficient biocide proper- ties [69]. The study indicated that both components are not miscible, the presence of the chitosan phase leads to slightly enhanced glass transition temperature for the zein phase. Zein/chitosan/Poly(vinyl pyrrolidone) (PVP) composite fibrous membranes were also fabricated from aqueous ethanol solutions by electrospinning [70]. PVP was introduced to facilitate the electrospinning process. Increasing zein and PVP concentrations led to an increase in average diameters of the fibers. In order to improve stability in wet stage and mechanical properties, the composite fibrous membranes could be crosslinked by hexamethylene diisocyanate (HDI). The crosslinked membranes showed slight morphological change after immersion in water for $24 \mathrm{~h}$. The tensile strength and elongation at break of the membranes were increased after crosslinking, whereas Young's modulus was decreased.

\subsection{Electrospinning of chitosan derivatives}

The spinnabilities are greatly improved by changing chitosan to its derivatives, because most of chitosan derivatives are soluble in water and (or) in a wide variety of common organic solvents. O-carboxymethyl chitosan (O-CMCS) is a water-soluble derivative of chitosan. It has good moisture retention, biocompatibility and antibacterial property, so it is a good biomaterial [71]. Du and Hsieh [72] synthesized O-CMCS with varying molecular weights and degrees of substitution by alkalization of chitosan, followed by carboxymethylation with monochloroacetic acid, and fabricated various $\mathrm{O}-\mathrm{CMCS} /$ water-soluble polymer blend nanofibers by electrospinning. The optimal fiber formation was observed at equal mass composition of O-CMCS (89 $\mathrm{kDa}$ at $0.36 \mathrm{DS}$ ) and PVA, producing nanofibers with an average diameter of $130 \mathrm{~nm}$. Heatinduced esterification (at $140^{\circ} \mathrm{C}$ for $30 \mathrm{~min}$ ) produced inter-molecular covalent cross-links within and among fibers, rendering the fibrous membrane water-insoluble. Membranes containing higher CMCS carboxyl to PVA hydroxyl ratio retained better fiber morphology upon extended water exposure, indicating more favorable inter-molecular cross-links. The fibrous membranes generated with less substituted CMCS were more hydrophilic and retained a greater extent of the desirable amine functionality. 
Similarly, the hybrids of N-carboxyethyl chitosan (N-CECS) and PVA could be made into nanofibers by electrospinning [73]. The electrospinning of CECS/PVA nanofibers was enabled by the ability of PVA to form an elastically deformable entanglement network based on hydrogen bonds. The average diameters of the bicomponent fibers were in the range $100-420 \mathrm{~nm}$. Water-resistant nanofibrous mats were obtained by thermal crosslinking at $100^{\circ} \mathrm{C}$ for $10 \mathrm{~h}$. Zhou et al. [74] prepared CECS/PVA nanofibers by electrospinning using water as solvent, The study indicated that there was strong intermolecular hydrogen bonding between the molecules of CECS and PVA. Electrospun N-CECS/polyacrylamide (PAAm) blend nanofibers have also been prepared [75].

Hexanoyl chitosan (H-CS) (Figure 2) has good blood compatibility and is anti-thrombogenic [76, 77], so it has been used for medical applications. Ultrafine H-CS fibers were successfully prepared by electrospinning of $\mathrm{H}-\mathrm{CS}$ solutions in chloroform [78]. The concentration of the spinning solutions was between 4 and 14\% w/v. The as-spun fibers appeared to be flat with ribbonlike morphology and average diameters in the range of $0.64-3.93 \mu \mathrm{m}$. The addition of an organic salt, pyridinium formate, helped to increase the conductivity of the spinning solution, which resulted in a general increase in the average diameter and a general decrease in the bead density of the resulting H-CS fibers. In addition, bead-free $\mathrm{H}-\mathrm{CS}$ /polylactide blend fibres were prepared by electrospinning from solutions in chloroform with the H-CS solution content of less than or equal to $50 \%(\mathrm{w} / \mathrm{w})$ [79]. Galactosylated chitosan (G-CS) (Figure 3) nanofibrous scaffold was also fabricated by electrospinning using formic acid as spinning solvent [80] for tissue engineering.

Ignatova et al. [81] fabricated quaternised chitosan (Q-CS)/PVA nanofibres by electrospinning of Q-CS solutions mixed with PVA. The average fibre diam-

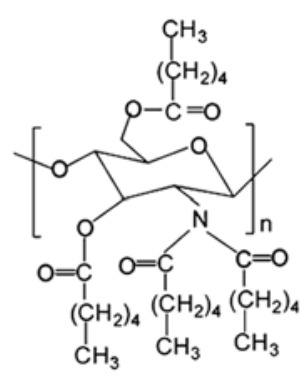

Figure 2. The molecular structure of Hexanoyl chitosan (H-CS)

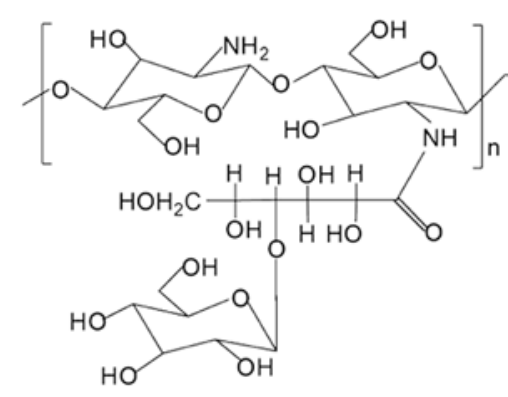

Figure 3. The molecular structure of Galactosylated chitosan (G-CS)

eter is in the range of 60-200 $\mathrm{nm}$. UV irradiation of the composite electrospun nanofibrous mats containing triethylene glycol diacrylate as crosslinking agent resulted in stabilising of the nanofibres against disintegration in water or water vapours. Similarly, Q-CS/PVP nanofibres were also prepared by electrospinning [82]. The average diameter of the fibers significantly decreases from 2800 to $1500 \mathrm{~nm}$ with increasing the polyelectrolyte content. The QCS/PVP fibers can also be crosslinked by incorporation of adding photo-crosslinking additives into spinning solutions and subsequent UV irradiation to the electrospun fibers. Another quaternised chitosan, N-[(2-hydroxy-3-trimethylammonium)propyl] chitosan chloride (HTCSC), is a water-soluble derivative of chitosan, which was synthesized via the reaction between glycidyl- trimethylammonium chloride and chitosan. Defect free HTCSC/PVA blend mats were prepared by electrospinning of an aqueous solution [83]. The average fibre diameter was in the range of $200-600 \mathrm{~nm}$, and decreases with increasing HTCSC content in the blends. The HTCSC/PVA nanofiber mats have a good antibacterial activity against Staphylococcus aureus and Escherichia coli.

Poly(chitosan-g-DL-lactic acid)(P(CS-g-LA)) copolymers which were produced by grafted DL-lactic acid onto chitosan were spun into submicron and/or nanofibers to fabricate scaffolds using an electrowet-spinning technique [84]. The diameter of the fibers in different scaffolds could vary from about $100 \mathrm{~nm}$ to around $3 \mu \mathrm{m}$. The scaffolds exhibited various pore sizes ranging from about $1 \mu \mathrm{m}$ to less than $30 \mu \mathrm{m}$ and different porosities up to $80 \%$. Significantly improved tensile strength and modulus for these fibrous scaffolds in their hydrated state were observed. Amino-reserved polycaprolactonegraft-chitosan (PCL-g-CS) (Figure 4) was synthe- 


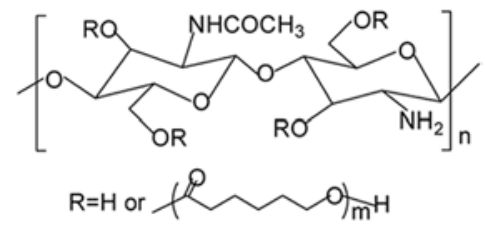

Figure 4. The molecular structure of amino-reserved polycaprolactone-graft-chitosan (PCL-g-CS)

sized by grafting $\varepsilon$-caprolactone oligomers onto the hydroxyl groups of CS via ring-opening polymerization by using methanesulfonic acid as solvent and catalyst [85]. PCL-g-CS exhibited good solubility in organic solvents, facilitating formation of PCL/PCL-g-CS blend nanofibers via electrospinning with the use of dimethylformamide (DMF)/ $\mathrm{CHCl}_{3}$ as solvents. Owing to the enhanced cellular attachment results from cationic amino groups, it is promising that these copolymers are ideal substances for developing drug carriers and tissue engineering scaffolds. Similarly, L-lactide-g-Chitosan (LLA-g-CS) which was prepared by grafting L-lactide oligomers via ring-opening polymerization was easily made into ultrafine fibers via electrospinning due to its solubility in a broad range of organic solvents [86].

\subsection{Electrospinning of blends of chitosan and inorganic nanoparticles}

A biomimetic nanocomposite nanofibers of hydroxyapatite(HAp)/chitosan was prepared by combining an in situ co-precipitation synthesis approach with an electrospinning process [87]. A model HAp/chitosan nanocomposite with the HAp mass ratio of $30 \mathrm{wt} \%$ was synthesized through the co-precipitation method so as to attain homogenous dispersion of the spindle-shaped HAp nanoparticles (ca. 100× $30 \mathrm{~nm}$ ) within the chitosan matrix. By using a small amount (10 wt $\%)$ of ultrahigh molecular weight poly(ethylene oxide) (UHMWPEO) as a fiber-forming facilitating additive, continuous HAp/chitosan nanofibers with a diameters of $214 \pm 25 \mathrm{~nm}$ were produced and the HAp nanoparticles with some aggregations were incorporated into the electrospun nanofibers. The crystalline nature of HAp remains and had survived the acetic acid-dominant solvent system. Similarly, Shen et al. [88] prepared uniform and ultrafine chitosan/PVA nanofibrous mats filled with HAp nanoparticles by electrospinning of blend solutions of HAp, chitosan and PVA. An increase in the contents of HAp nanoparticles from 0 to $0.5 \mathrm{wt} \%$ caused the conductivity of the blend solution to increase from 1.06 to $2.27 \mathrm{mS} / \mathrm{cm}$, and the average diameter of the composite fibers to decrease from $59 \pm 10$ to $49 \pm 10 \mathrm{~nm}$. The results indicated that some particles had filled in the nanofibers whereas the others had dispersed on the surface of fibers. Similar chitosan/PVA/HAp nanofibrous biocomposite scaffolds were fabricated by Yang et al. [89]. The scaffolds have porous nanofibrous morphology with random fibers in the range of 100$700 \mathrm{~nm}$ diameters. Increase the content of HAp up to $2 \%$ increased the ultimate tensile strength and tensile modulus, but further increase HAp caused the decrease of tensile strength and tensile modulus. Another biomimetic material of HAp with electrospun chitosan/PVA nanofibrous scaffolds was prepared by using chitosan/PVA electrospun membranes as organic matrix, and HAp was formed in supersaturated $\mathrm{CaCl}_{2}$ and $\mathrm{KH}_{2} \mathrm{PO}_{4}$ solution [90]. It was found that addition of poly (acrylic acid) (PAA) to the mineral solution and use of matrix with $\mathrm{N}$ carboxyethyl chitosan (N-CECS) promoted mineral growth and distribution of HAp.

A fairly uniform silver nanoparticles (AgNPs)/chitosan/PEO ultrafine fibers were prepared by electrospinning of chitosan/PEO solutions containing $\mathrm{Ag} /$ chitosan colloids by means of in situ chemical reduction of Ag ions [91]. The AgNPs were evenly distributed in chitosan/PEO ultrafine fibers with the size less than $5 \mathrm{~nm}$. The existence of $\mathrm{Ag}-\mathrm{O}$ bond in the composite ultrafine fibers led to the tight combination between Ag and chitosan. Penchev et al. [92] prepared Hybrid nanofibers from chitosan or CECS, AgNPs and PEO by electrospinning using formic acid as solvent. AgNPs were synthesized in situ in the spinning solution. The results showed that AgNPs are uniformly dispersed in the nanofibers. The surface of the nanofibers was enriched in chitosan and $15 \mathrm{wt} \%$ of the incorporated AgNPs were on the fiber surface. Similar AgNPs/chitosan/PVA nanofiber mats [93] and AgNPs/chitosan/gelatin nanofibers [94] were also fabricated. Montmorillonite (MMT) has good dispersion properties, can be widely used in macromolecular industry as an additive. Chitosan/MMT nanocomposites have been prepared for adsorption [95] and drug release [96] due to the unique properties of MMT. Submicron fibers of the composites of PVA, chi- 
tosan oligosaccharide (COS) and MMT were prepared using electrospinning method with aqueous solutions [97]. The PVA/COS ratio and MMT concentration play important roles in nanofiber mat properties. The exfoliated MMT layers were welldistributed within nanofibers. It was also found that the mechanical property and thermal stability were increased with COS and MMT contents.

Another interesting nanomaterial is multiwalled carbon nanotubes (MWCNTs). MWCNTs grafted by chitosan (MWCNTs-g-CS) could disperse well in poly(vinyl alcohol) (PVA) aqueous solution with $2 \%(\mathrm{v} / \mathrm{v})$ acetic acid solution. The solution containing PVA and MWCNTs-g-CS could be electrospun to nanofibers [98]. It was found that the electrospinning process did not severely alter the electron hybridization of carbon atoms within the nanotube framework. Moreover, these nanofibers showed a novel sheath-core structure, the outer and inner diameters of these sheath-core nanofibers were about 200 and $100 \mathrm{~nm}$, respectively. The electrospun nanofiber mats displayed faster electron transfer kinetics and better electrochemical properties than its cast film, which justified further applications in biological areas.

Other nanofibers electrospun of blends of chitosan and inorganic nanoparticles are not discussed in detail here, such as titanium dioxide $\left(\mathrm{TiO}_{2}\right)$ nanoparticles/chitosan/PVA electrosun nanofibers exhibiting antibacterial activities against Staphylococcus aureus and Escherichia coli [99], palladium nanoparticles/chitosan grafting acrylic copolymer (PdNPs/ CS-g-AA) blend electrospun nanofibrous catalyst applied to catalyze alpha-octene hydrogenation in normal temperature and pressure [100], etc. The combination of the characteristics of the inorganic nanoparticles and the features of chitosan nanofibers could lead to more products with unique properties that can fit special needs. This method may be one of the most important directions of the development of chitosan electrospinning techniques.

\section{Applications of chitosan nanofibers \\ 3.1. Enzyme immobilization:}

Electrospun nanofibers have been proven to be excellent supports for enzyme immobilization because they can provide large surface area-to-volume ratios, pore sizes tailored to protein molecule dimensions, functionalized surfaces, multiple sites for interaction or attachment, and low mass-transfer limitation [101]. Huang et al. [30] fabricated nanofibrous membrane from mixed chitosan/PVA solution by electrospinning. The membrane was treated by removing most of PVA from the nascent one with $0.5 \mathrm{M} \mathrm{NaOH}$ aqueous solution. The stabilized chitosan nanofibrous membrane was explored as support for enzyme immobilization due to the characteristics of excellent biocompatibility, high surface/volume ratio and large porosity. Lipase from Candida rugosa was immobilized on the nanofibrous membrane using glutaraldehyde (GA) as coupling reagent. The lipase loading on this nanofibrous membrane was up to $63.6 \mathrm{mg} / \mathrm{g}$ and the activity retention of the immobilized lipase was $49.8 \%$ under the optimum condition. The $\mathrm{pH}$ and thermal stabilities of lipase were improved after it was immobilized on the membrane. In addition, the experimental results of reusability and storage stability indicated that the residual activities of the immobilized lipase were $46 \%$ after 10 cycles and $56.2 \%$ after 30 days, which were obviously higher than that of the free one.

\subsection{Filtration}

Nanofibers containing chitosan have the advantage of filtering material based on the high surface/volume ratio, large porosity and functionality. They can be potentially applicable in a wide variety of filtration applications ranging from water purification media to air filter media [102]. Pure chitosan nanofiber mats fabricated by electrospinning using trifluoroacetic acid (TFA) as solvent have been used for absorbing metal ions [16]. The as-spun nanofiber ( $\sim 235 \mathrm{~nm}$ in diameter) mats which were neutralized with potassium carbonate showed good erosion stability in water and high adsorption affinity for metal ions in an aqueous solution. The adsorption data of $\mathrm{Cu}$ (II) and $\mathrm{Pb}$ (II) were fitted well with Langmuir isotherm indicating that mono-layer adsorption occurred on the nanofiber mats. The equilibrium adsorption capacities (from Langmuir isotherm data) for $\mathrm{Cu}$ (II) and $\mathrm{Pb}$ (II) were 485.44 and $263.15 \mathrm{mg} / \mathrm{g}$, respectively. The $\mathrm{Cu}(\mathrm{II})$ adsorption data were $\sim 6$ and $\sim 11$ times higher than the previously reported highest values of chitosan microsphere $(80.71 \mathrm{mg} / \mathrm{g})$ [103] and the plain chitosan $(45.20 \mathrm{mg} / \mathrm{g})$ [104], respectively. This high adsorp- 
tion capacity suggests that the chitosan electrospun nanofiber mats can be applied to filter out (or neutralize) toxic metal ions and microbes without losing their original chitosan properties such as biocompatibility, hydrophilicity, bioactivity, non-antigenicity, and non-toxicity.

Desai et al. [105] fabricated nanofibrous filter media by electrospinning of chitosan/PEO blend solutions onto a spunbonded non-woven polypropylene substrate. Filter media with varying fiber diameter and filter basis weight were obtained. Heavy metal binding, anti-microbial and physical filtrations efficiencies of the filter media were correlated with the surface chemistry and physical characteristics of the filter media. Filtration efficiency of the nanofiber mats was strongly related to the size of the fibers and its surface chitosan content. Hexavalent chromium binding capacities up to $35 \mathrm{mg} / \mathrm{g}$ chitosan were exhibited by the filter media along with a 2-3 $\log$ reduction in Escherichia coli bacteria cfu (clonal formation unit). The filter media showed high efficiencies to air and water filtration, which correlated with the fibrous media size and shape. Similar nonwoven fiber mats with fiber diameter as low as $80 \pm 35 \mathrm{~nm}$ for air and water filtration were also made by electrospinning high molecular weight chitosan/PEO (95:5) blends [106].

An affinity membrane made from electrospun hybrid chitosan/nylon-6 nanofibers by nucleophilic reaction of the chitosan's hydroxyl and amidocyanogen with the triazinyl chloride of Cibacron Blue F3GA (CB) ligand was used to study the purification of papain [107]. The equilibrium adsorption capacity (from Langmuir isotherm data) for papain was $93.46 \mathrm{mg} / \mathrm{g}$ affinity membrane. Fifteen layers of the composite affinity membrane were packed into a spin column to separate papain from raw material. Significant amount of the adsorbed papain (about $90.4 \%$ ) was eluted by $1.0 \mathrm{M} \mathrm{NaSCN}$ at $\mathrm{pH} 9.0$, and 4.8-fold purification was achieved in a single step. It is shown that this system has the potential to be developed for the industrial purification of the papain.

\subsection{Wound dressing}

Zhou et al. [74] prepared biocompatible carboxyethyl chitosan(CECS)/PVA nanofibers by electrospinning of aqueous CECS/PVA solution. The potential use of the fiber mats as scaffolding materials for skin regeneration was evaluated in vitro using mouse fibroblasts (L929) as reference cell lines. Indirect cytotoxicity assessment of the fiber mats indicated that the CECS/PVA electrospun mat was nontoxic to the L929 cell. Cell culture results showed that fibrous mats were good in promoting the cell attachment and proliferation. This novel electrospun matrix would be used as potential wound dressing for skin regeneration. The chitosan/ collagen/PEO nanofibrous membrane fabricated by electrospinning and then crosslinked by glutaraldehyde vapor have potential as a wound dressing for skin regeneration [62]. The membrane showed no cytotoxicity toward growth of 3T3 fibroblasts and had good in vitro biocompatibility. From animal studies, the membrane was better than gauze and commercial collagen sponge wound dressing in wound healing rate.

Ignatova et al. [81] prepared quaternised chitosan (Q-CS)/PVA nanofibres containing triethylene glycol diacrylate as crosslinking agent and which were further irradiated by UV irradiation. Microbiological screening demonstrated the antibacterial activity of the photo-crosslinked electrospun mats against Gram-positive bacteria Staphylococcus aureus and Gram-negative bacteria Escherichia coli. Similarly, Photo-crosslinked QCS/PVP electrospun mats show high antibacterial activity against the Staphylococcus aureus and Escherichia coli [82]. These obtained nanofibrous electrospun mats are promising for wound healing applications.

A wound dressing material composed of silver nanoparticles (AgNPs) and chitosan has been fabricated using a nanometer and self-assembly technology [108]. It could significantly increase the rate of wound healing. To develop a better wound dressing, fairly uniform AgNPs/chitosan/PEO ultrafine fibers were successfully prepared [91]. Evaluation of antimicrobial activities of the electrospun AgNPs/ chitosan/PEO fibrous membrane against Escherichia coli showed that the AgNPs in the ultrafine fibers significantly enhanced the inactivation of bacteria. The fibrous membrane was better than other wound dressing containing AgNPs in wound healing rate. Similarly, higher antibacterial activity was observed in the electrospun non-woven mats of AgNPs/ $\mathrm{PVA} / \mathrm{CS}$ blends than in those of PVA/CS blends [93]. The as spun mats are also excellent wound dressing. 


\subsection{Tissue engineering}

The development of bioinspired or biomimetic materials is essential and has formed one of the most important fields in today's tissue engineering research. Hydroxyapatite (HAp) is a well known biomimetic material. A biomimetic nanocomposite nanofibers of HAp/chitosan was prepared by combining an in situ co-precipitation synthesis approach with an electrospinning process [87]. Biological in vitro cell culture with human fetal osteoblast cells for up to 15 days demonstrated that the incorporation of HAp nanoparticles into chitosan nanofibrous scaffolds led to significant bone formation oriented outcomes compared to that of the pure electrospun chitosan scaffolds. The nanofibers are of potential interest for bone tissue engineering applications. Yang et al. [89] prepared chitosan/PVA/ HAp nanofibrous biocomposite scaffolds by electrospinning. The attachment and growth of mouse fibroblast on the Surface of the nanofibrous structure indicated that a combination of nanofibrous CS/PVA and HAp that mimics the nanoscale features of the extracellular matrix could be promising for application as scaffolds for tissue regeneration, especially in low or non load bearing areas. Another biomimetic chitosan/PVA/HAp nanofibrous scaffold prepared by using chitosan/PVA electrospun membranes as organic matrix and HAp being formed in supersaturated $\mathrm{CaCl}_{2}$ and $\mathrm{KH}_{2} \mathrm{PO}_{4}$ solution is also of potential application in the field of biomedicine [90].

Based on a biomimetic approach, Mohammadi et al. [49] developed 3D nanofibrous hybrid scaffolds consisting of PCL, PVA and chitosan (PCL/PVA/ CS scaffolds) via a multi-jet electrospinning method. Osteogenically induced cultures revealed that cells were well-attached, penetrated into the framework and were uniformly distributed. Besides, PCL nanofibers containing various amounts of chitosan $(0,3$, 9, and 23\%) were also prepared and evaluated for their osteogenic differentiation of preosteoblasts in $2 \mathrm{D}$ and $3 \mathrm{D}$ cultures [47]. The results revealed that incorporation of chitosan in PCL nanofibers not only improved the adhesion and proliferation of MC 3T3-E1 cells but also elevated calcium deposition, alkaline phosphatase activity, and the expression of osteopontin compared to PCL alone nanofibers. The nanofibers are superior to PCL nanofibers in promoting bone tissue formation. The chitosan/
PLA micro/nanofibers prepared by electrospinning.are also expected to be used in the native extracellular matrix for tissue engineering [51].

Bridging of nerve gaps after injury is a major problem in peripheral nerve regeneration. Electrospun $\mathrm{PCL} /$ chitosan nanofibrous scaffolds were evaluated in vitro using rat Schwann cells (RT4-D6P2T) for nerve tissue engineering [109]. The Young's modulus and strain at break of the electrospun PCL/chitosan nanofibers were better than those of the chitosan nanofibers. PCL/chitosan scaffolds showed better cell proliferation than PCL scaffolds $(48 \%$ more cell proliferation after 8 days of culture) and maintained their characteristic cell morphology, with spreading bipolar elongations to the nanofibrous substrates. This electrospun nanofibrous matrix was proved of specific interest in tissue engineering for peripheral nerve regeneration.

Electrospun chitosan nano/microfibrous tubes with a degree of deacetylation (DD) of 93\% were examined the effects of their mechanical strength and permeability on nerve regeneration [110]. The study indicated that the chitosan nano/microfiber mesh tubes with a DD of $93 \%$ have sufficient mechanical properties to preserve tube space, provide a better scaffold for cell migration and attachment, and facilitate humoral permeation to enhance nerve regeneration. Afterwards, Wang et al. [111] constructed a chitosan nonwoven nanofiber mesh tube consisting of oriented fibers by the electrospinning method. The efficacy of oriented nanofibers on Schwann cell alignment and positive effect of this tube on peripheral nerve regeneration were confirmed. As a result of fiber orientation, the tensile strength along the axis of the sheet increased. Because Schwann cells aligned along the nanofibers, oriented fibrous sheets could exhibit a Schwann cell column. Functional recovery and electrophysiological recovery occurred in the oriented nanofibers and approximately matched those in the isograft. The oriented chitosan nanofiber mesh tube may be a promising substitute for autogenous nerve graft.

Liver tissue engineering requires a perfect extracellular matrix for primary hepatocytes culture to maintain high level of liver specific functions and desirable mechanical stability. Galactosylated chitosan (G-CS) nanofibrous scaffold was fabricated by electrospinning using formic acid as spinning solvent [80]. The G-CS nanofibrous scaffolds dis- 
played slow degradation and suitable mechanical properties as an extracellular matrix for hepatocytes. Hepatocytes cultured on G-CS nanofibrous scaffold formed stably immobilized 3D flat aggregates and exhibited superior cell bioactivity with higher levels of liver-specific function maintenance in terms of albumin secretion, urea synthesis and cytochrome P-450 enzyme than 3D spheroid aggregates formed on G-CS films. Such G-CS-based nanofibrous scaffolds could be useful for various applications such as bioartificial liver-assist devices and tissue engineering for liver regeneration as primary hepatocytes culture substrates.

Ultra-fine fiber mats of hexanoyl chitosan (H-CS) for potential use as skin tissue scaffolds was fabricated [112]. The results showed that the fiber mats were non-toxic and did not release substances harmful to mouse fibroblasts (L929). The fibrous scaffolds could support the attachment and the proliferation of both human keratinocytes (HaCaT) and human foreskin fibroblasts (HFF), especially for $\mathrm{HaCaT}$. In addition, the cells cultured on the fibrous scaffolds exhibited normal cell shapes and integrated well with surrounding fibers. The obtained results confirmed the potential for use of the fiber mats as scaffolds for skin tissue engineering.

Duan et al. [113, 114] prepared nanofibrous composite membranes of poly(lactide-co-glycolide) (PLGA)/chitosan/PVA by electrospinning. In their studies, PLGA and chitosan/PVA were simultaneously electrospun from two different syringes and mixed on the rotating drum. Then membrane was crosslinked by glutaraldehyde vapor. Cell culture indicated that the cells could not only favorably attach and grow well on the composite membranes, but were also able to migrate and infiltrate the membranes. Therefore, the results suggest that the composite membranes can positively mimic the structure of natural extracellular matrices and have the potential for application as three-dimensional tissue engineering scaffolds.

\subsection{Drug delivery}

Electrospun nanofibers are better drug delivery systems than the bulk materials due to the high specific surface area and short diffusion passage length. The drug release rate can be finely controlled by modulation of nanofiber morphology, porosity and composition. The blends of poly(ethylene glycol)-g-chi- tosan (PEG-g-CS) and ibuprofen-loaded poly(lactideco-glycolide) (PLGA) were made into fiber mats by electrospinning [115]. It was found that the glass transition temperature of PLGA decreased with increasing PEG-g-CS content in the composite membranes, which results in decrease in tensile stress at break but increase in tensile strain of the membranes. The degree of shrinkage of these composite membranes decreased from 76 to only $3 \%$ when the PEG-g-CS content in the membranes increased from 10 to $30 \%$. The presence of PEG-gCS significantly moderated the burst release rate of ibuprofen from the electrospun PLGA membranes. Moreover, ibuprofen could be conjugated to the side chains of PEG-g-CS to prolong its release for more than two weeks. The sustained release capacity of the PLGA/PEG-g-CS composite membranes, together with their compliant and stable mechanical properties, renders them ideal matrices for atrial fibrillation.

Nanofibrous materials containing the antitumor drug doxorubicin hydrochloride (DOX) were prepared using a one-step method by electrospinning of DOX/quaternized chitosan (Q-CS)/poly(1-lactide-co-d,l-lactide)(coPLA) solutions [116]. The release rate of DOX from the prepared fibers increased with the increase in DOX content. The DOX release process was diffusion-controlled. The studies revealed that incorporation of DOX and Q$\mathrm{CS}$ in the nanofibrous mats led to a significant reduction in the HeLa cells viability. It was found that the antitumor efficacy of the DOX-containing mats at $6 \mathrm{~h}$ was higher than that of the free DOX. Chitosan/hydroxybenzotriazole(HOBt)/PVA blend nanofibers may be suitable for drug delivery or tissue engineering applications too [117].

For effective cancer gene therapy, systemic administration of tumor-targeting adenoviral (Ad) complexes is critical for delivery to both primary and metastatic lesions. Electrospinning was used to generate nanocomplexes of Ad/chitosan/poly(ethylene glycol) (PEG)/folic acid (FA) for effective FA receptor-expressing tumor-specific transduction [118]. The transduction efficiency of Ad/chitosanPEG-FA was increased as a function of FA ratio in FA receptor-expressing $\mathrm{KB}$ cells, but not in FA receptor-negative U343 cells, demonstrating FA receptor-targeted viral transduction. In addition, the transduction efficiency of Ad/chitosan/PEG/FA was 
$57.2 \%$ higher than chitosan-encapsulated Ad, showing the superiority of FA receptor-mediated endocytosis for viral transduction. The production of inflammatory cytokine, IL-6 from macrophages was significantly reduced by $\mathrm{Ad} /$ chitosan/PEG/FA nanocomplexes, implying the potential for use in systemic administration. These results clearly demonstrate that cancer cell-targeted viral transduction by $\mathrm{Ad} /$ chitosan/PEG/FA nanocomplexes can be used effectively for metastatic tumor treatment with reduced immune reaction against Ad.

\subsection{Catalysis}

A nanofibrous catalyst was fibricated by electrospinning of Chitosan grafting acrylic acid copolymer (CS-g-AA) supporting nano palladium [100]. The diameter of nanofiber was about $70-200 \mathrm{~nm}$, the size of metal particles were in a range of 10$40 \mathrm{~nm}$, and palladium particles dispersed on nanofibers homogeneously. The catalyst was applied to catalyze alpha-octene hydrogenation in normal temperature and pressure. The results showed that the conversion of alpha-octene was 99 percent, and the yield of octane was 65 percent by double-metal catalyst. This indicated the excellent catalysis efficiency of the nanofibrous catalyst. Another nanofibrous catalyst was also prepared by Shan et al. [119]. Chitosan nanofibers were used to modify indium tin oxide (ITO) electrode by electrospinning. Then, Prussian blue (PB) nanoparticles were electrodeposited on the nanofibers by potentiostatic technique in an acidic solution containing single ferricyanide. The modified electrode exhibited electrocatalytic activity towards reduction of $\mathrm{H}_{2} \mathrm{O}_{2}$.

\section{Conclusions and perspectives}

Chitosan is soluble in most of acid solutions. The protonation of the amino groups on the chitosan backbone inhibits the spinnability of pure chitosan. There are several ways to overcome the defect restricting the formation of continuous fibers. One is to use a special solvent (such as concentrated acetic acid solution) to reduce the surface tension of chitosan solution and increase the electrostatic charge density of the jet. The second is to change the amino groups of chitosan into salts directly in the solvent (e.g. TFA as solvent) to decrease the free amino groups of chitosan. The third is to mix chitosan with other substances (such as synthetic polymers, proteins, etc.), so that the free amino groups of chitosan are reduced by the intermolecular interactions between chitosan and the additives through some form, such as hydrogen bonds. The fourth is to change chitosan into its derivatives. The solubilities of chitosan derivatives have been greatly improved, thus the spinnabilities are also greatly improved. The nanofibers containing chitosan have potential use in the areas of enzyme immobilization, filtration, wound dressing, tissue engineering, drug delivery and catalysis not only because chitosan is a non-toxic, antibacterial, biodegradable and biocompatible biopolymer, but also because the nanofibers have large surface areas and high porosity (Table 1).

During the past few years, enormous progress has been made in the area of electrospinning to produce various nanofibres containing chitosan with unique shape and unique properties. However, there are many problems that need to be solved for largescale manufacturing of chitosan based new nanofibers, such as: how to fabricate uniform nanofibers with same morphologies, mechanical and chemical properties repeatedly and massively. How to improve the mechanical properties of chitosan nanofibers and how to avoid the toxicity arised from the toxic spinning solvents which will limit the applications of as-spun nanofibrous products, etc. Designing mixtures containing chitosan and other substances as electrospinning materials, adjusting various parameters of the spinning process to control the fiber diameter, orientation and morphology of the electrospun nanofibers, searching for 'green solvents' without toxicity as electrospinning solvents and further modifying the as spun nanofiber products to improve the characteristics will perhaps be focused by researchers. With the applications of new electrospinning technologies (such as in-situ mixing electrospinning, two-phase electrospinning, wind assisted electrospinning and coaxial electrospinning, etc.), abundant novel nanofibrous pruducts based on chitosan would be designed and the applications of the products which are still at the laboratory level will became true in near future by the efforts of researchers. 
Table 1. Chitosan based nanofibers and their applications

\begin{tabular}{|c|c|c|c|c|c|}
\hline Polymer & Solvent & DD & $\begin{array}{l}\text { Average fiber diameter } \\
\text { (nanoparticle size) [nm] }\end{array}$ & Application & Reference \\
\hline Chitosan & aq AA & 54 & 130 & - & [17] \\
\hline Chitosan & aq AA & $75-85$ & $70 \pm 45$ & - & [18] \\
\hline Chitosan & TFA/DCM & 95 & $130 \pm 10$ & - & [15] \\
\hline Chitosan & TFA/DCM & 85 & $126 \pm 20$ & tissue engineering & [14] \\
\hline $\begin{array}{l}\text { Chitosan } \\
\text { (neutralized with } \mathrm{K}_{2} \mathrm{CO}_{3} \text { solution) }\end{array}$ & TFA & 86.7 & 235 & filtration & [16] \\
\hline $\begin{array}{l}\text { Chitosan/PVA } \\
\text { (removing PVA with } 0.5 \mathrm{M} \mathrm{NaOH} \text { ) }\end{array}$ & aq AA & 90 & $80 \sim 150$ & enzyme immobilization & {$[30]$} \\
\hline Chitosan/PVA & aq AA & 90 & $99 \pm 21$ & wound dressings & [33] \\
\hline Chitosan/PEO & aq AA & 80 & $10-240$ & - & {$[39,40]$} \\
\hline Chitosan/PEO & aq AA & $67-83$ & $80 \pm 35$ & filtration & {$[105,106]$} \\
\hline $\begin{array}{l}\text { Chitosan/ UHMWPEO }(5 \%) \\
\text { Chitosan/ UHMWPEO }(10 \%) \\
\text { Chitosan/ UHMWPEO }(20 \%)\end{array}$ & aq AA/DMSO & $>85$ & $\begin{array}{l}114 \pm 19 \\
138 \pm 15 \\
102 \pm 14\end{array}$ & - & [43] \\
\hline Chitosan/PET & TFA & 85 & $500-800$ & wound dressings & [45] \\
\hline Chitosan/PCL & HFIP & $75-85$ & $450 \pm 110$ & bone tissue engineering & [47] \\
\hline Chitosan/PCL & HFIP/TFA/DCM & - & $190 \pm 26$ & nerve tissue engineering & [109] \\
\hline Chitosan/nylon-6 & HFIP/FA & 85 & $80-310$ & filtration & {$[54,107]$} \\
\hline $\begin{array}{l}\text { Chitosan/PVA-PCL } \\
\text { (by multi-jet electrospinning method) }\end{array}$ & aq $\mathrm{AA} / \mathrm{CHCl}_{3}$ & 85 & $100-200$ & bone tissue engineering & [49] \\
\hline $\begin{array}{l}\text { Chitosan/PVA-PLGA } \\
\text { (by multi-jet electrospinning method) }\end{array}$ & $\begin{array}{l}\text { aq AA } \\
\text { THF/DMF }\end{array}$ & 90 & $275 \pm 175$ & tissue engineering & {$[113,114]$} \\
\hline $\begin{array}{l}\text { Chitosan/collagen } \\
\text { (crosslinked by GA vapor) }\end{array}$ & HFIP/TFA & 85 & $434-691$ & tissue engineering & [61] \\
\hline $\begin{array}{l}\text { Chitosan/collagen/PEO } \\
\text { (crosslinked by GA vapor) }\end{array}$ & aq AA & 95 & $398 \pm 76$ & wound dressings & {$[62]$} \\
\hline Chitosan/SF & FA & 86 & $180-790$ & - & [67] \\
\hline O-CMCS/PVA & water & 84.7 & 130 & - & [72] \\
\hline N-CECS/PVA & water & 82.5 & $131-456$ & wound dressings & [74] \\
\hline $\mathrm{H}-\mathrm{CS}$ & $\mathrm{CHCl}_{3}$ & 88 & 640-3930 & skin tissue engineering & {$[78,112]$} \\
\hline G-CS & FA & 85 & 160 & liver tissue engineering & [80] \\
\hline $\begin{array}{l}\text { Q-CS/PVA } \\
\text { (crosslinked by UV irradiation) }\end{array}$ & aq AA & 80 & $60-200$ & wound dressings & [81] \\
\hline $\begin{array}{l}\text { Q-CS/PVP } \\
\text { (crosslinked by UV irradiation) }\end{array}$ & water & 80 & $2400 \pm 640$ & wound dressings & [82] \\
\hline Q-CS)/coPLA & DMF/DMSO & 80 & 470 & drug delivery & {$[116]$} \\
\hline PCL-g-CS/PCL & $\mathrm{DMF} / \mathrm{CHCl}_{3}$ & 91 & - & tissue engineering & [85] \\
\hline PEG-g-CS/ PLGA & DMF & 85 & - & drug delivery & [115] \\
\hline CS-HOBt/PVA & water & 85 & $190-282$ & drug delivery & [117] \\
\hline Chitosan/HAp/UHMWPEO & aq AA/DMSO & $>85$ & $214 \pm 25(100 \times 30)$ & bone tissue engineering & [87] \\
\hline Chitosan/HAp/PVA & aq AA & 91 & $49 \pm 10(-)$ & bone tissue engineering & [88] \\
\hline Chitosan/HAp/PVA & aq AA/DMSO & 88 & $100-700(-)$ & bone tissue engineering & [89] \\
\hline Chitosan/PEO/AgNPs & aq AA & 80 & $\sim 100(<5)$ & wound dressings & [91] \\
\hline Chitosan/gelatin/AgNPs & aq AA & 87 & $220-400(2-10)$ & wound dressings & [94] \\
\hline CS-g-AA/ PaNPs & aq AA & 78 & $70-200(10-40)$ & catalyst & {$[100]$} \\
\hline
\end{tabular}

Abbrevitions: THF, tetrahydrofuran, aq AA, aqueous acetic acid solution; DMSO: dimethyl sulfoxide. Other abbrevitions are in the text.

\section{Acknowledgements}

We are grateful to the Scientific \& Technological Support Project of Sichuan Province (No. 2009GZ0167) for financial support of this work.

\section{References}

[1] Formhals A.: Process and apparatus for preparing artificial thread. U.S. Patent 1975504, USA (1934).
[2] Doshi J., Reneker D. H.: Electrospinning process and applications of electrospun fibers. Journal of Electrostatics, 35, 151-160 (1995).

DOI: $10.1109 /$ IAS.1993.299067

[3] Deitzel J. M., Kleinmeyer J. D., Hirvonen J. K., Tan B. N. C.: Controlled deposition of electrospun poly(ethylene oxide) fibers. Polymer, 42, 8163-8170 (2001).

DOI: $\underline{10.1016 / \mathrm{S} 0032-3861(01) 00336-6}$ 
[4] Deitzel J. M., Kleinmeyer J., Harris D., Tan B. N. C.: The effect of processing variables on the morphology of electrospun nanofibers and textiles. Polymer, 42, 261-272 (2001).

DOI: $10.1016 / \mathrm{S} 0032-3861(00) 00250-0$

[5] Frenot A., Chronakis I. S.: Polymer nanofibers assembled by electrospinning. Current Opinion in Colloid and Interface Science, 8, 64-75 (2003). DOI: $10.1016 / \mathrm{S} 1359-0294(03) 00004-9$

[6] Hunley M. T., Long T. E.: Electrospinning functional nanoscale fibers: A perspective for the future. Polymer International, 57, 385-389 (2008).

DOI: $10.1002 /$ pi.2320

[7] Mi F-L., Tan Y-C., Liang H-F., Sung H-S.: In vivo biocompatibility and degradability of a novel injectable- chitosan-based implant. Biomaterials, 23, 181-191 (2002). DOI: $10.1016 / \mathrm{S} 0142-9612(01) 00094-1$

[8] Angelova N., Manolova N., Rashkov I., Maximova V., Bogdanova S., Domard A.: Preparation and properties of modified chitosan films for drug release. Journal of Bioactive and Compatible Polymers, 10, 285-298 (1995). DOI: $10.1177 / 088391159501000401$

[9] Selmer-Olsen E., Ratnaweera H. C., Pehrson R.: A novel treatment process for dairy wastewater with chitosan produced from shrimp-shell waste. Water Science and Technology, 34, 33-40 (1996). DOI: 10.1016/S0273-1223(96)00818-9

[10] Min B. M., Lee S. W., Lim J. N., You Y., Lee T. S., Kang P. H., Park W. H.: Chitin and chitosan nanofibers: Electrospinning of chitin and deacetylation of chitin nanofibers. Polymer, 45, 7137-7142 (2004). DOI: $10.1016 /$ j.polymer.2004.08.048

[11] Ohkawa K., Cha D., Kim H., Nishida A., Yamamoto H.: Electrospinning of chitosan. Macromolecular Rapid Communications, 25, 1600-1605 (2004). DOI: $10.1002 /$ marc. 200400253

[12] Hasegawa M., Isogai A., Onabe F., Usuda M.: Dissolving states of cellulose and chitosan in trifluoroacetic acid. Journal of Applied Polymer Science, 45, 1857-1863 (1992). DOI: 10.1002/app.1992.070451020

[13] Ohkawa K., Minato K-I., Kumagai G., Hayashi S., Yamamoto H.: Chitosan nanofiber. Biomacromolecules, 7, 3291-3294 (2006).

DOI: $10.1021 / \mathrm{bm} 0604395$

[14] Sangsanoh P., Suwantong O., Neamnark A., Cheepsunthornc P., Pavasantd P., Supaphola P.: In vitro biocompatibility of electrospun and solvent-cast chitosan substrata towards Schwann, osteoblast, keratinocyte and fibroblast cells. European Polymer Journal, 46, 428-440 (2010).

DOI: $10.1016 /$ j.eurpolymj.2009.10.029
[15] Sangsanoh P., Supaphol P.: Stability improvement of electrospun chitosan nanofibrous membranes in neutral or weak basic aqueous solutions. Biomacromolecules, 7, 2710-2714 (2006).

DOI: $10.1021 / \mathrm{bm} 0602861$

[16] Haider S., Park S-Y.: Preparation of the electrospun chitosan nanofibers and their applications to the adsorption of $\mathrm{Cu}(\mathrm{II})$ and $\mathrm{Pb}(\mathrm{II})$ ions from an aqueous solution. Journal of Membrane Science, 328, 90-96 (2009).

DOI: $\underline{10.1016 / \mathrm{j} . \mathrm{memsci} .2008 .11 .046}$

[17] Geng X., Kwon O-H., Jang J.: Electrospinning of chitosan dissolved in concentrated acetic acid solution. Biomaterials, 26, 5427-5432 (2005).

DOI: $10.1016 /$ j.biomaterials.2005.01.066

[18] Vrieze S. D., Westbroeak P., Camp T. V., Van Langenhove L.: Electrospinning of chitosan nanofibrous structures: Feasibility study. Journal of Materials Science, 42, 8029-8034 (2007).

DOI: $10.1007 / \mathrm{s} 10853-006-1485-6$

[19] Homoyoni H., Ravandi S. A. H., Valizadeh M.: Electrospinning of chitosan nanofibers: Processing optimization. Carbohydrate Polymers, 77, 656-661 (2009). DOI: $\underline{10.1016 / \text { j.carbpol.2009.02.008 }}$

[20] Schiffman J. D., Schauer C. L.: Cross-linking chitosan nanofibers. Biomacromolecules, 8, 594-601 (2007).

DOI: $10.1021 / \mathrm{bm} 060804 \mathrm{~s}$

[21] Schiffman J. D., Schauer C. L.: One-step electrospinning of cross-linked chitosan fibers. Biomacromolecules, 8, 2665-2667 (2007).

DOI: $10.1021 / \mathrm{bm} 7006983$

[22] Fong H., Chun I., Reneker D. H.: Beaded nanofibers formed during electrospinning. Polymer, 40, 45854592 (1999).

DOI: $10.1016 / \mathrm{S} 0032-3861(99) 00068-3$

[23] Lin T., Wang H., Wang H., Wang X.: The charge effect of cationic surfactants on the elimination of fibre beads in the electrospinning of polystyrene. Nanotechnology, 15, 1375-1381 (2004).

DOI: $10.1088 / 0957-4484 / 15 / 9 / 044$

[24] Son W. K., Youk J. H., Lee T. S., Park W. H.: The effects of solution properties and polyelectrolyte on electrospinning of ultrafine poly(ethylene oxide) fibers. Polymer, 45, 2959-2966 (2004).

DOI: $10.1016 /$ j.polymer.2004.03.006

[25] Jia Y-T., Gong J., Gu X-H., Kim H-Y., Dong J., Shen $\mathrm{X}-\mathrm{Y}$.: Fabrication and characterization of poly (vinyl alcohol)/chitosan blend nanofibers produced by electrospinning method. Carbohydrate Polymers, 67, 403-409 (2007).

DOI: $\underline{10.1016 / \text { j.carbpol.2006.06.010 }}$ 
[26] Allen M. J., Schoonmaker J. E., Bauer T. W., Williams P. F., Higham P. A., Hansen Y.: Preclinical evaluation of a poly (vinyl alcohol) hydrogel implant as a replacement for the nucleus pulposus. Spine, 29, 515-523 (2004).

DOI: $10.1097 / 01 . B R S .0000113871 .67305 .38$

[27] Chen D-H., Leu J-C., Huang T-C.: Transport and hydrolysis of urea in a reactor-separator combining an anion-exchange membrane and immobilized urease. Journal of Chemical Technology and Biotechnology, 61, 351-357 (1994).

DOI: $10.1002 /$ jctb.280610411

[28] Li L., Hsieh Y-L.: Chitosan bicomponent nanofibers and nanoporous fibers. Carbohydrate Research, 341, 374-381(2006).

DOI: $\underline{10.1016 / \text { j.carres.2005.11.028 }}$

[29] Zhou Y. S., Yang D., Nie J.: Electrospinning of chitosan/poly(vinyl alcohol)/acrylic acid aqueous solutions. Journal of Applied Polymer Science, 102, 5692-5697 (2006).

DOI: $10.1002 /$ app. 25068

[30] Huang X-J., Ge D., Xu Z-K.: Preparation and characterization of stable chitosan nanofibrous membrane for lipase immobilization. European Polymer Journal, 43, 3710-3718 (2007).

DOI: 10.1016/j.eurpolymj.2007.06.010

[31] Zheng H., Du Y., Yu J., Huang R., Zhang L.: Preparation and characterization of chitosan/poly(vinyl alcohol) blend fibers. Journal of Applied Polymer Science, 80, 2558-2565 (2001). DOI: $10.1002 /$ app. 1365

[32] Lin T., Fang J., Wang H., Wang X.: Using chitosan as a thickener for electrospinning dilute PVA solutions to improve fibre uniformity. Nanotechnology, 17, 3718-3723 (2006). DOI: $10.1088 / 0957-4484 / 17 / 15 / 017$

[33] Zhang Y., Huang X., Duan B., Wu B., Li S., Juan X.: Preparation of electrospun chitosan/poly(vinyl alcohol) membranes. Colloid and Polymer Science, 285, 855-863 (2007). DOI: 10.1007/s00396-006-1630-4

[34] Zhou Y. S., Yang D. Z., Nie J.: Preparation and characterization of crosslinked chitosan-based nanofibers. Chinese Chemical Letters, 18, 118-120 (2007). DOI: $10.1016 /$ j.cclet.2006.11.035

[35] Sims C. D., Butler P. E., Casanova R., Lee B. T., Randolph M. A., Lee W. P., Vacanti C. A., Yaremchuk M. J.: Injectable cartilage using polyethylene oxide polymer substrates. Plastic and Reconstructive Surgery, 98, 843-850 (1996).

[36] Yoshii F., Zhansahan Y., Isobe K., Shinozaki K., Makuuchi K.: Electron beam crosslinked PEO and PEO/PVA hydrogels for wound dressing. Radiation Physics and Chemistry, 55, 133-138 (1999). DOI: $10.1016 / \mathrm{S} 0969-806 X(98) 00318-1$
[37] Klossner R. R., Queen H. A., Coughlin A. J., Krause W. E.: Correlation of chitosan's rheological properties and its ability to electrospin. Biomacromolecules, $\mathbf{9}$, 2947-2953 (2008).

DOI: $10.1021 / \mathrm{bm} 800738 \mathrm{u}$

[38] Bhattarai N., Edmondson D., Veiseh O., Matsenb F. A., Zhang M.: Electrospun chitosan-based nanofibers and their cellular compatibility. Biomaterials, 26, 6176-6184 (2005).

DOI: $10.1016 /$ j.biomaterials.2005.03.027

[39] Kriegel C., Kit K. M., McClements D. J., Weiss J.: Electrospinning of chitosan-poly(ethylene oxide) blend nanofibers in the presence of micellar surfactant solutions. Polymer, 50, 189-200 (2009).

DOI: 10.1016/j.polymer.2008.09.041

[40] Kriegel C., Kit K. M., McClements D. J., Weiss J.: Influence of surfactant type and concentration on electrospinning of chitosan-poly(ethylene oxide) blend nanofibers. Food Biophysics, 4, 213-228 (2009).

DOI: 10.1007/s11483-009-9119-6

[41] Zhang J-F., Yang D-Z., Xu F., Yin R-X., Nie J.: Electrospun core-shell structure nanofibers from homogeneous solution of poly(ethylene oxide)/chitosan. Macromolecules, 42, 5278-5284 (2009).

DOI: $10.1021 / \mathrm{ma} 900657 \mathrm{y}$

[42] Duan B., Dong C., Yuan X., Yao K.: Electrospinning of chitosan solutions in acetic acid with poly(ethylene oxide). Journal of Biomaterials Science, Polymer Edition, 15, 797-811 (2004).

DOI: $10.1163 / 156856204774196171$

[43] Zhang Y. Z., Su B., Ramakrishna S., Lim C. T.: Chitosan nanofibers from an easily electrospinnable UHMWPEO-doped chitosan solution system. Biomacromolecules, 9, 136-141 (2008). DOI: $10.1021 / \mathrm{bm} 701130 \mathrm{e}$

[44] Yang M-R., Chen K-S., Tsai J-C., Tseng C-C., Lin SF.: The antibacterial activities of hydrophilic modified nonwoven PET. Materials Science and Engineering: C, 20, 167-173 (2002). DOI: $10.1016 / \mathrm{S} 0928-4931(02) 00028-0$

[45] Jung K-H., Huh M-W., Meng W., Yuan J., Hyun S. H., Bae J-S., Hudson S. M., Kang I-K.: Preparation and antibacterial activity of PET/chitosan nanofibrous mats using an electrospinning technique. Journal of Applied Polymer Science, 105, 2816-2823 (2007). DOI: 10.1002/app.25594

[46] Lopes-da-Silva J. A., Veleirinho B., Delgadillo I.: Preparation and characterization of electrospun mats made of PET/chitosan hybrid nanofibers. Journal of Nanoscience and Nanotechnology, 9, 3798-3804 (2009). DOI: $10.1166 /$ jnn.2009.NS70 
[47] Yang X. C., Chen X. N., Wang H. J.: Acceleration of osteogenic differentiation of preosteoblastic cells by chitosan containing nanofibrous scaffolds. Biomacromolecules, 10, 2772-2778 (2009).

DOI: $10.1021 / \mathrm{bm} 900623 \mathrm{j}$

[48] Shalumon K. T., Anulekha K. H., Girish C. M., Prasantha R., Naira S. V., Jayakumar R.: Single step electrospinning of chitosan/poly( $\varepsilon$-caprolactone) nanofibers using formic acid/acetone solvent mixture. Carbohydrate Polymers, 80, 413-419 (2010). DOI: $10.1016 /$ j.carbpol.2009.11.039

[49] Mohammadi Y., Soleimani M., Fallahi-Sichani M., Gazme A., Haddadi-Asl V., Arefian E., Kiani J., Moradi R., Atashi A., Ahmadbeigi N.: Nanofibrous poly(E-caprolactone)/poly(vinyl alcohol)/chitosan hybrid scaffolds for bone tissue engineering using mesenchymal stem cells. The International Journal of Artificial Organs, 30, 204-211 (2007).

[50] Oksman K., Skrifvars M., Selin J-F.: Natural fibres as reinforcement in polylactic acid (PLA) composites. Composites Science and Technology, 63, 1317-1324 (2003). DOI: $10.1016 / \mathrm{S} 0266-3538(03) 00103-9$

[51] Xu J., Zhang J. H., Gao W. Q., Liang H., Wang H., Li J.: Preparation of chitosan/PLA blend micro/nanofibers by electrospinning. Materials Letters, 63, 658660 (2009).

DOI: $10.1016 /$ j.matlet.2008.12.014

[52] Chen F., Li X. Q., Mo X. M., He C., Wang H., Ikada Y.: Electrospun chitosan-P(LLA-CL) nanofibers for biomimetic extracellular matrix. Journal of Biomaterials Science, Polymer Edition, 19, 677-691 (2008). DOI: $10.1163 / 156856208784089661$

[53] Ryu Y. J., Kim H. Y., Lee K. H., Park H. C., Lee D. R.: Transport properties of electrospun nylon 6 nonwoven mats. European Polymer Journal, 39, 1883-1889 (2003).

DOI: 10.1016/S0014-3057(03)00096-X

[54] Zhang H. T., Li S. B., Christopher J., Ning X., Nie H., Zhu L.: Studies on electrospun nylon-6/chitosan complex nanofiber interactions. Electrochimica Acta, 54, 5739-5745 (2009).

DOI: 10.1016/j.electacta.2009.05.021

[55] Mohammed Z. H., Hember M. W. N., Richardson R. K., Morris E. R.: Application of polymer blending laws to composite gels of agarose and crosslinked waxy maize starch. Carbohydrate Polymers, 36, 2736 (1998).

DOI: $10.1016 / \mathrm{S} 0144-8617(98) 00012-5$

[56] Teng S-H., Wang P., Kim H-E.: Blend fibers of chitosan-agarose by electrospinning. Materials Letters, 63, 2510-2512 (2009).

DOI: $10.1016 /$ j.matlet.2009.08.051
[57] Rho K. S., Jeong L., Lee G., Seod B-M., Park Y. J., Hong S-D., Roh S., Cho J. J., Park W. H., Min B-M.: Electrospinning of collagen nanofibers: Effects on the behavior of normal human keratinocytes and earlystage wound healing. Biomaterials, 27, 1452-1461 (2006).

DOI: 10.1016/j.biomaterials.2005.08.004

[58] Chen Z. G., Mo X. M., Qing F. L.: Electrospinning of collagen-chitosan complex. Materials Letters, 61, 3490-3494 (2007).

DOI: 10.1016/j.matlet.2006.11.104

[59] Chen Z. G., Mo X. M., He C. L., Wang H.: Intermolecular interactions in electrospun collagen-chitosan complex nanofibers. Carbohydrate Polymers, 72, 410-418 (2008).

DOI: $10.1016 /$ j.carbpol.2007.09.018

[60] Chen Z. G., Wei B., Mo X. M., Ramakrishna S., Cui F.: Mechanical properties of electrospun collagenchitosan complex single fibers and membrane. Materials Science and Engineering: C, 29, 2428-2435 (2009).

DOI: $10.1016 /$ j.msec.2009.07.006

[61] Chen Z. G., Wang P. W., Wei B., Cui F. Z.: Electrospun collagen-chitosan nanofiber: A biomimetic extracellular matrix for endothelial cell and smooth muscle cell. Acta Biomaterialia, 6, 372-382 (2010). DOI: $10.1016 /$ j.actbio.2009.07.024

[62] Chen J-P., Chang G-Y., Chen J-K.: Electrospun collagen/chitosan nanofibrous membrane as wound dressing. Colloids and Surfaces A: Physicochemical and Engineering Aspects, 313-314, 183-188 (2008). DOI: 10.1016/j.colsurfa.2007.04.129

[63] Santin M., Motta A., Freddi G., Cannas M.: In vitro evaluation of the inflammatory potential of the silk fibroin. Journal of Biomedical Materials Research, 46, 382-389 (1999).

DOI: $10.1002 /($ SICI) 1097-4636(19990905)46:3<382:: AID-JBM11>3.0.CO;2-R

[64] Wang Y. Z., Kim H-J., Vunjak-Novakovic G., Kaplan D. L.: Stem cell-based tissue engineering with silk biomaterials. Biomaterials, 27, 6064-6082 (2006). DOI: 10.1016/j.biomaterials.2006.07.008

[65] Park W. H., Ha W. S., Ito H., Miyamoto T., Inagaki H., Noishiki Y.: Relationships between antithrombogenicity and surface free energy of regenerated silk fibroin films. Fibers and Polymers, 2, 58-63 (2001). DOI: $10.1007 / \mathrm{BF} 02875259$

[66] Sukigara S., Gandhi M., Ayutsede J., Micklus M., Ko F.: Regeneration of Bombyx mori silk by electrospinning - Part 1: Processing parameters and geometric properties. Polymer, 44, 5721-5727 (2003). DOI: $10.1016 / \mathrm{S} 0032-3861(03) 00532-9$ 
[67] Park W. H., Jeong L., Yoo D., Hudson S.: Effect of chitosan on morphology and conformation of electrospun silk fibroin nanofibers. Polymer, 45, 7151-7157 (2004).

DOI: 10.1016/j.polymer.2004.08.045

[68] Torres-Giner S., Gimenez E., Lagaron J. M.: Characterization of the morphology and thermal properties of Zein Prolamine nanostructures obtained by electrospinning. Food Hydrocolloids, 22, 601-614 (2008). DOI: $10.1016 /$ j.foodhyd.2007.02.005

[69] Torres-Giner S., Ocio M. J., Lagaron J. M.: Novel antimicrobial ultrathin structures of zein/chitosan blends obtained by electrospinning. Carbohydrate Polymers, 77, 261-266 (2009).

DOI: $10.1016 /$ j.carbpol.2008.12.035

[70] Song T. Y., Yao C., Li X. S.: Electrospinning of zein/chitosan composite fibrous membranes. Chinese Journal of Polymer Science, 28, 171-179 (2010). DOI: $10.1007 / \mathrm{s} 10118-010-8239-2$

[71] Chen R-N., Wang G-M., Chen C-H., Ho H-O., Sheu M-T.: Development of N,O-(carboxymethyl)chitosan/ collagen matrixes as a wound dressing. Biomacromolecules, 7, 1058-1064 (2006). DOI: $10.1021 / \mathrm{bm} 050754 \mathrm{~b}$

[72] Du J., Hsieh Y-L.: Nanofibrous membranes from aqueous electrospinning of carboxymethyl chitosan. Nanotechnology, 19, 125707/1-125707/9 (2008). DOI: 10.1088/0957-4484/19/12/125707

[73] Mincheva R., Manolova N., Rashkov I.: Bicomponent aligned nanofibers of $N$-carboxyethylchitosan and poly(vinyl alcohol). European Polymer Journal, 43, 2809-2818 (2007).

DOI: $10.1016 /$ j.eurpolymj.2007.04.020

[74] Zhou Y. S., Yang D., Chen X., Xu Q., Lu F., Nie J.: Electrospun water-soluble carboxyethyl chitosan/ poly(vinyl alcohol) nanofibrous membrane as potential wound dressing for skin regeneration. Biomacromolecules, 9, 349-354 (2008).

DOI: $10.1021 / \mathrm{bm} 7009015$

[75] Mincheva R., Manolova N., Paneva D., Rashkov I.: Preparation of polyelectrolyte-containing nanofibers by electrospinning in the presence of a non-ionogenic water-soluble polymer. Journal of Bioactive and Compatible Polymers, 20, 419-435 (2005).

DOI: $10.1177 / 0883911505057447$

[76] Lee K. Y., Ha W. S., Park W. H.: Blood compatibility and biodegradability of partially $N$-acylated chitosan derivatives. Biomaterials, 16, 1211-1216 (1995). DOI: $10.1016 / 0142-9612(95) 98126-Y$

[77] Hirano S., Noishiki Y.: The blood compatibility of chitosan and $\mathrm{N}$-acylchitosans. Journal of Biomedical Materials Research, 19, 413-417 (1985). DOI: $10.1002 / j b m .820190406$

[78] Neamnark A., Rujiravanit R., Supaphol P.: Electrospinning of hexanoyl chitosan. Carbohydrate Polymers, 66, 298-305 (2006).

DOI: $10.1016 /$ j.carbpol.2006.03.015
[79] Peesan M., Rujiravanit R., Supaphol P.: Electrospinning of hexanoyl chitosan/polylactide blends. Journal of Biomaterials Science, Polymer Edition, 17, 547565 (2006).

DOI: $10.1163 / 156856206776986251$

[80] Feng Z. Q., Chu X., Huang N. P., Wang T., Wang Y., Shi X., Ding Y., Gu Z-Z.: The effect of nanofibrous galactosylated chitosan scaffolds on the formation of rat primary hepatocyte aggregates and the maintenance of liver function. Biomaterials, 30, 2753-2763 (2009).

DOI: $10.1016 /$ j.biomaterials.2009.01.053

[81] Ignatova M., Starbova K., Markova N., Manolova N., Rashkov I.: Electrospun nano-fibre mats with antibacterial properties from quaternised chitosan and poly (vinyl alcohol). Carbohydrate Research, 341, 2098-2107 (2006).

DOI: $10.1016 /$ j.carres.2006.05.006

[82] Ignatova M., Manolova N., Rashkov I.: Novel antibacterial fibers of quaternized chitosan and poly(vinyl pyrrolidone) prepared by electrospinning. European Polymer Journal, 43, 1112-1122 (2007). DOI: $10.1016 /$ j.eurpolymj.2007.01.012

[83] Alipour S. M., Nouri M., Mokhtari J., Bahrami S. H.: Electrospinning of poly(vinyl alcohol)-water-soluble quaternized chitosan derivative blend. Carbohydrate Research, 344, 2496-2501 (2009). DOI: $10.1016 /$ j.carres.2009.10.004

[84] Wan Y., Cao X. Y., Zhang S. M., Wang S., Wu Q.: Fibrous poly(chitosan-g-dl-lactic acid) scaffolds prepared via electro-wet-spinning. Acta Biomateriala, 4, 876-886 (2008).

DOI: $10.1016 /$ j.actbio.2008.01.001

[85] Duan K. R., Chen H. L., Huang J., Yu j., Liu S., Wang D., Li Y.: One-step synthesis of amino-reserved chitosan-graft-polycaprolactone as a promising substance of biomaterial. Carbohydrate Polymers, 80, 498-503 (2010).

DOI: $10.1016 /$ j.carbpol.2009.12.013

[86] Skotak M., Leonov A. P., Larsen G., Noriega S., Subramanian A.: Biocompatible and biodegradable ultrafine fibrillar scaffold materials for tissue engineering by facile grafting of 1-lactide onto chitosan. Biomacromolecules, 9, 1902-1908 (2008).

DOI: $10.1021 / \mathrm{bm} 800158 \mathrm{c}$

[87] Zhang Y. Z., Venugopal J. R., El-Turki A., Ramakrishna S., Su B., Lim C. T.: Electrospun biomimetic nanocomposite nanofibers of hydroxyapatite/chitosan for bone tissue engineering. Biomaterials, 29, 43144322 (2008).

DOI: $10.1016 /$ j.biomaterials.2008.07.038

[88] Shen K., Hu Q. L., Chen L., Shen J.: Preparation of chitosan bicomponent nanofibers filled with hydroxyapatite nanoparticles via electrospinning. Journal of Applied Polymer Science, 115, 2683-2690 (2010). DOI: $\underline{10.1002 / a p p .29832}$ 
[89] Yang D. Z., Jin Y., Ma G. P., Chen X., Lu F., Nie J.: Fabrication and characterization of chitosan/PVA with hydroxyapatite biocomposite nanoscaffolds. Journal of Applied Polymer Science, 110, 3328-3335 (2008). DOI: 10.1002/app.28829

[90] Yang D. Z., Jin Y., Zhou Y. S., Ma G., Chen X., Lu F., Nie J.: In situ mineralization of hydroxyapatite on electrospun chitosan-based nanofibrous scaffolds. Macromolecular Bioscience, 8, 239-246 (2008).

DOI: 10.1002/mabi.200700221

[91] An J., Zhang H., Zhang J. T., Zhao Y., Yuan X.: Preparation and antibacterial activity of electrospun chitosan/poly(ethylene oxide) membranes containing silver nanoparticles. Colloid and Polymer Science, 287, 1425-1434 (2009).

DOI: 10.1007/s00396-009-2108-y

[92] Penchev H., Paneva D., Manolova N., Rashkov I.: Electrospun hybrid nanofibers based on chitosan or $\mathrm{N}$-carboxyethylchitosan and silver nanoparticles. Macromolecular Bioscience, 9, 884-894 (2009).

DOI: $10.1002 / \mathrm{mabi} .200900003$

[93] Hang A. T., Tae B., Park J. S.: Non-woven mats of poly(vinyl alcohol)/chitosan blends containing silver nanoparticles: Fabrication and characterization. Carbohydrate Polymers, 82, 472-479 (2010).

DOI: $10.1016 /$ j.carbpol.2010.05.016

[94] Zhuang X. P., Cheng B. W., Kang W. M., Xu X.: Electrospun chitosan/gelatin nanofibers containing silver nanoparticles. Carbohydrate Polymers, 82, 524-527 (2010).

DOI: $10.1016 /$ j.carbpol.2010.04.085

[95] Wang L., Wang A. Q.: Adsorption characteristics of Congo Red onto the chitosan/montmorillonite nanocomposite. Journal of Hazardous Materials, 147, 979-985 (2007). DOI: 10.1016/j.jhazmat.2007.01.145

[96] Liu K-H., Liu T-Y., Chen S-Y., Liu D-M.: Drug release behavior of chitosan-montmorillonite nanocomposite hydrogels following electrostimulation. Acta Biomaterialia, 4, 1038-1045 (2008). DOI: 10.1016/j.actbio.2008.01.012

[97] Park J. H., Lee H. W., Chae D. K., Oh W., Yun J. D., Deng Y., Yeum J. H.: Electrospinning and characterization of poly(vinyl alcohol)/chitosan oligosaccharide/clay nanocomposite nanofibers in aqueous solutions. Colloid and Polymer Science, 287, 943-950 (2009).

DOI: $10.1007 / \mathrm{s} 00396-009-2050-\mathrm{Z}$

[98] Feng W., Wu Z. G., Li Y., Feng Y., Yuan X.: The fabrication and electrochemical properties of electrospun nanofibers of a multiwalled carbon nanotube grafted by chitosan. Nanotechnology, 19, 105707/1105707/6 (2008).

DOI: $\underline{10.1088 / 0957-4484 / 19 / 10 / 105707}$
[99] Son B., Yeom B. Y., Song S. H., Lee C-S., Hwang T. S.: Antibacterial electrospun chitosan/poly(vinyl alcohol) nanofibers containing silver nitrate and titanium dioxide. Journal of Applied Polymer Science, 111, 2892-2899 (2009).

DOI: 10.1002/app.29233

[100] Yu J. X., Liu T. Q.: Preparation of chitosan grafting acrylic acid supported palladium fibrous catalyst and its application in hydrogenation. Materials Science Forum, 620-622, 537-540 (2009).

DOI: 10.4028/www.scientific.net/MSF.620-622.537

[101] Wang Z. G., Wan L. S., Liu Z. M., Huang X-J., Xu ZK.: Enzyme immobilization on electrospun polymer nanofibers: An overview. Journal of Molecular Catalysis B: Enzymatic, 56, 189-195 (2009). DOI: $10.1016 /$ j.molcatb.2008.05.005

[102] Desai K., Kit K.: Effect of spinning temperature and blend ratios on electrospun chitosan/poly(acrylamide) blends fibers. Polymer, 49, 4046-4050 (2008). DOI: $10.1016 /$ j.polymer.2008.07.012

[103] Wan Ngah W. S., Endud C. S., Mayanar R.: Removal of copper(II) ions from aqueous solution onto chitosan and cross-linked chitosan beads. Reactive and Functional Polymers, 50, 181-190 (2002). DOI: 10.1016/S1381-5148(01)00113-4

[104] Huang C., Chung Y-C., Liou M-R.: Adsorption of $\mathrm{Cu}$ (II) and $\mathrm{Ni}$ (II) by pelletized biopolymer. Journal of Hazardous Materials, 45, 265-277 (1996). DOI: 10.1016/0304-3894(95)00096-8

[105] Desai K., Kit K., Li J. J., Davidson P. M., Zivanovic S., Meyer H.: Nanofibrous chitosan non-wovens for filtration applications. Polymer, 50, 3661-3669 (2009).

DOI: $\underline{10.1016 / j . p o l y m e r .2009 .05 .058}$

[106] Desai K., Kit K., Li J., Zivanovic S.: Morphological and surface properties of electrospun chitosan nanofibers. Biomacromolecules, 9, 1000-1006 (2008). DOI: $10.1021 / \mathrm{bm} 701017 \mathrm{z}$

[107] Zhang H. T., Wu C. Y., Zhang Y. L., White C. J. B., Xue Y., Nie H., Zhu L.: Elaboration, characterization and study of a novel affinity membrane made from electrospun hybrid chitosan/nylon-6 nanofibers for papain purification. Journal of Materials Science, 45, 2296-2304 (2010).

DOI: $10.1007 / \mathrm{s} 10853-009-4191-3$

[108] Lu S. Y., Gao W. J., Gu H. Y.: Construction, application and biosafety of silver nanocrystalline chitosan wound dressing. Burns, 34, 623-628 (2008). DOI: 10.1016/j.burns.2007.08.020

[109] Prabhakaran M. P., Venugopal J. R., Chyan T. T., Hai L. B., Chan C. K., Lim A. Y., Ramakrishn S.: Electrospun biocomposite nanofibrous scaffolds for neural tissue engineering. Tissue Engineering Part A, 14, 1787-1797 (2008).

DOI: $10.1089 /$ ten.tea.2007.0393 
[110] Wang W., Itoh S., Matsuda A., Ichinose S., Shinomiya K., Hata Y., Tanaka J.: Influences of mechanical properties and permeability on chitosan nano/microfiber mesh tubes as a scaffold for nerve regeneration. Journal of Biomedical Materials Research Part A, 84, 557-566 (2008).

DOI: $10.1002 / \mathrm{jbm} . \mathrm{a} .31536$

[111] Wang W., Itoh S., Konno K., Kikkawa T., Ichinose S., Sakai K., Ohkuma T., Watabe K.: Effects of Schwann cell alignment along the oriented electrospun chitosan nanofibers on nerve regeneration. Journal of Biomedical Materials Research Part A, 91, 994-1005 (2009). DOI: $10.1002 / \mathrm{jbm} . a .32329$

[112] Neamnark A., Sanchavanakit N., Pavasant P., Rujiravanita R., Supaphola P.: In vitro biocompatibility of electrospun hexanoyl chitosan fibrous scaffolds towards human keratinocytes and fibroblasts. European Polymer Journal, 44, 2060-2067 (2008).

DOI: 10.1016/j.eurpolymj.2008.04.016

[113] Duan B., Yuan X., Zhu Y., Zhang Y., Li X., Zhang Y., Yao K.: A nanofibrous composite membrane of PLGA-chitosan/PVA prepared by electrospinning. European Polymer Journal, 42, 2013-2022 (2006). DOI: $10.1016 / j$.eurpolymj.2006.04.021

[114] Duan B., Wu L., Li X., Yuan X., Li X., Zhang Y., Yao K.: Degradation of electrospun PLGA-chitosan/PVA membranes and their cytocompatibility in vitro. Journal of Biomaterials Science, Polymer Edition, 18, 95115 (2007).

DOI: $\underline{10.1163 / 156856207779146105}$
[115] Jiang H., Fang D., Hsiao B., Chu B., Chen W.: Preparation and characterization of ibuprofen-loaded poly(lactide-co-glycolide)/poly(ethylene glycol)- $g$ chitosan electrospun membranes. Journal of Biomaterials Science, Polymer Edition, 15, 279-296 (2004). DOI: $10.1163 / 156856204322977184$

[116] Ignatova M. G., Manolova N. E., Toshkova R. A., Rashkov I. B., Gardeva E. G., Yossifova L. S., Alexandrov M. T.: Electrospun nanofibrous mats containing quaternized chitosan and polylactide with in vitro antitumor activity against HeLa cells. Biomacromolecules, 11, 1633-1645 (2010).

DOI: $10.1021 / \mathrm{bm} 100285 \mathrm{n}$

[117] Charernsriwilaiwat N., Opanasopit P., Rojanarata T., Ngawhirunpata T., Supaphol P.: Preparation and characterization of chitosan-hydroxybenzotriazole/polyvinyl alcohol blend nanofibers by the electrospinning technique. Carbohydrate Polymers, 81, 675-680 (2010).

DOI: $10.1016 /$ j.carbpol.2010.03.031

[118] Park Y., Kang E., Kwon O-J., Hwang T., Park H., Leed J. M., Kim J. H., Yun C-O.: Ionically crosslinked Ad/chitosan nanocomplexes processed by electrospinning for targeted cancer gene therapy. Journal of Controlled Release, 148, 75-82 (2010).

DOI: $10.1016 /$ j.jconrel.2010.06.027

[119] Shan Y. P., Yang G. C., Gong J., Zhang X., Zhu L., Qu L.: Prussian blue nanoparticles potentiostatically electrodeposited on indium tin oxide/chitosan nanofibers electrode and their electrocatalysis towards hydrogen peroxide. Electrochimica Acta, 53, 77517755 (2008).

DOI: $10.1016 /$ j.electacta.2008.05.035 